\title{
Knowledge Gaps Update to the 2019 IPCC Special Report on the Ocean and Cryosphere: Prospects to Refine Coastal Flood Hazard Assessments and Adaptation Strategies With At-Risk Communities of Alaska
}

\author{
Dee M. Williams ${ }^{1 * \dagger}$ and Li H. Erikson ${ }^{2 \dagger}$ \\ ${ }^{1}$ Alaska Regional Office, United States Geological Survey, Anchorage, AK, United States, ${ }^{2}$ Pacific Coastal and Marine \\ Science Center, United States Geological Survey, Santa Cruz, CA, United States
}

\section{OPEN ACCESS}

Edited by:

Matthew Collins,

University of Exeter, United Kingdom

Reviewed by:

Alessandro Stocchino,

Hong Kong Polytechnic University,

Hong Kong SAR, China

Henry P. Huntington,

Independent Researcher, Eagle River,

United States

*Correspondence:

Dee M. Williams

dmwilliams@usgs.gov

tThese authors have contributed equally to this work

Specialty section:

This article was submitted to Predictions and Projections,

a section of the journal

Frontiers in Climate

Received: 19 August 2021 Accepted: 01 November 2021 Published: 03 December 2021

Citation:

Williams DM and Erikson LH (2021) Knowledge Gaps Update to the 2019 IPCC Special Report on the Ocean and Cryosphere: Prospects to Refine

Coastal Flood Hazard Assessments and Adaptation Strategies With At-Risk Communities of Alaska. Front. Clim. 3:761439. doi: 10.3389/fclim.2021.761439
This article reviews the status of knowledge gaps and co-production process challenges that impede coastal flood hazard resilience planning in communities of northwestern Alaska, where threat levels are high. Discussion focuses on the state of knowledge arising after preparation of the 2019 IPCC Special Report on the Ocean and Cryosphere in a Changing Climate and highlights prospects to address urgent needs. The intent is to identify some key steps necessary to advance the integration of relevant multidisciplinary observations with flood modeling and infrastructure mapping to co-produce new online hazard and risk assessment tools that inform local community planning and improve science collaboration among Federal, state, and regional partners for enhanced pre-storm preparations and post-storm recovery, including partial or complete relocation. By focusing coastal data integration for delivery of priority geospatial hazard map products through a consistent yet customized approach to adaptation planning, the broad collaborative effort in Alaska may yield a path of stakeholder service delivery that can be applied to many Arctic communities and other vulnerable regions of the world.

Keywords: climate change, coastal flood modeling, resilience planning, Alaska native communities, co-production of knowledge

\section{INTRODUCTION}

Coastal areas throughout the world are increasingly vulnerable to rising sea level and storm events that threaten lives and property, destroy infrastructure, disrupt local economies, and alter ecosystem services. But due to a combination of rising sea level, diminished sea ice, changing wind patterns, beach and bluff erosion, permafrost thaw, and anthropogenic stressors, the dangers have become especially acute for many Arctic and sub-arctic communities in Alaska. Western and northern Alaska coastlines are experiencing some of the world's highest erosion rates (Gibbs and Richmond, 2017; Jones et al., 2020) compounded with increasing coastal flood hazards that have demanded action as a top priority for regional adaptation and resilience planning efforts over the last decade (Immediate Action Work Group, 2009; U.S. Army Corps of Engineers, 2009). As erosion of coastal permafrost throughout the circumpolar Arctic region intensifies, the case of 
Alaska warrants more national and international attention in the study and application of climate resilience pathways.

In 2019, the Denali Commission Statewide Threat Assessment reported that 38 Alaska Native communities now face serious and immediate flooding threats to their residents, resources, public health, and infrastructure, 25 of which are situated along the western and northern coastline (University of Alaska Fairbanks Institute of Northern Engineering, 2019). Statewide, the report indicates that as many as 144 Alaska Native communities are likely to experience some degree of local infrastructure damage from erosion, flooding, and/or permafrost thaw, with 79 under serious immediate threat from compound vulnerabilities. Preliminary economic projections estimate that such damages to Alaska infrastructure, without adaptation measures, are likely to cost $\$ 5.5$ billion through the end of the century (Melvin et al., 2017), while subsequent additional economic analysis estimates it will cost on average $\$ 50-\$ 100$ million per year for at-risk Alaska communities to protect infrastructure and relocate in response to growing environmental threats (Berman and Schmidt, 2019). More than 15 years ago, the U.S. Army Corps of Engineers identified seven coastal communities (Bethel, Dillingham, Kaktovik, Kivalina, Newtok, Shishmaref, and Unalakleet) likely to require eventual relocation, with three of them (Newtok, Kivalina, Shishmaref) vulnerable to total loss within 15 years (U.S. Army Corps of Engineers, 2006). The U.S. Government Accountability Office (GAO), reflecting on the national scale of an emerging problem, recently documented the pressing need for Federal leadership on climate-forced internal displacement already occurring within the United States (U.S. Government Accountability Office, 2020). In a parallel but connected national initiative, the November 2019 Presidential Memorandum on Ocean Mapping of the United States Exclusive Economic Zone and the Shoreline and Nearshore of Alaska calls for the development of more seamless coastal mapping data in Alaska by 2030, leading to the recent compilation of an Alaska Coastal Mapping Strategic Plan (Alaska Mapping Executive Committee, 2020).

In addition to coastal flood hazards in Alaska, other physical challenges are compounded by numerous social challenges that impede viable options for local mitigation and adaptation responses. Alaska village populations are generally small (wellunder 1,000 residents), geographically isolated (no connecting road system), may lack the technical expertise and staffing to protect existing infrastructure, and rarely have backup facilities or reserve utilities in the event of failure (Buzard et al., 2021a). Most villages have small cash economies and only limited employment opportunities because cash-paying jobs tend to be few and unstable (temporary or seasonal). The combination of low population density and high mitigation expense creates an economic cost-benefit calculus that generally disqualifies these communities from mainstream disaster assistance programs (U.S. Congress, 2007; Bronen and Chapin, 2013; Buzard et al., 2021a). Further, slow but ongoing environmental change is not typically considered a disaster as defined by the Stafford Disaster Relief and Emergency Assistance Act, which constitutes the statutory authority for most Federal disaster response activities, thus creating additional barriers for small population communities to access funding and technical assistance needed for coastal flooding hazards. Invisibility under the law also occurs when hazard protection programs favor the standard model of private property owners to the disadvantage of alternative models such as a tribal organization, creating real linkages between obstacles to adaptation planning and constructed vulnerability (Marino, 2012). Thus, more than other coastal communities in the U.S. facing the growing risks of flood exposure, Alaska Native communities are typically threatened with plausible total loss scenarios, raising consideration for at least partial or even complete village relocation. Social justice issues are also uniquely entrained with coastal flood hazards in Alaska because the potential adverse consequences fall so disproportionately on minority populations in a manner that could seriously undermine socio-cultural and linguistic continuity. Also relevant is that many of the now vulnerable Alaska Native communities were originally established in their current location because of earlier government interventions to settle migrant peoples around school facilities and other infrastructure that could be constructed in places most easily accessed by barge transport, as opposed to locations chosen by the communities themselves that may have been less vulnerable to environmental change (Marino, 2012; Bronen et al., 2020).

For all these reasons, the threatening situation in Alaska creates mounting urgency to develop more collaborative, integrated, and innovative approaches to reduce risk and promote resilience. Coastal communities realize the need for adaptation strategies, but many are unsure how to begin and don't have ready access to the specific help they need. For example, results from a recent web-based questionnaire indicate that Western science deliverables and hazard assessment trainings do not generally meet the needs of small community planners among tribal participants in Alaska (Kettle et al., 2019). Findings based on the analysis of 21 responses show that participants consistently desire more detailed and locally specific climate science information, and they need it presented in a more understandable format. Responsive adjustments to such feedback are underway in multiple formats (e.g., see Alaska Tribal Resilience Network ${ }^{1}$ ). Ongoing research across the nation identifies multiple common barriers to adaptation planning that frequently arise from a wide range of institutional, social, economic, and other factors (Shi et al., 2015; Meerow and Woodruff, 2020). Despite the reality that flooding constitutes the most frequent natural hazard in the United States (Kousky et al., 2020), there is not yet an integrated national structure to manage that growing threat in coastal areas, although Alaska does benefit from the integrative work of the Denali Commission, an independent Federal agency established by Congress in 1998 to provide economic support to rural Alaska ${ }^{2}$.

\footnotetext{
${ }^{1}$ https://akcasc.org/aktrln

${ }^{2}$ In 2015, the Obama Administration directed the Denali Commission to establish a Village Infrastructure Protection (VIP) Program and tasked it to coordinate assistance for rural Alaskan communities in their efforts to become more resilient. Since then, the Commission website reports providing about $\$ 40$ million of appropriated funds to support the program, while leveraging an additional $\$ 55.7$ million from other sources for VIP related work (Denali Commission, VIP Program online fact sheet). In partnership with Alaska's Department of
} 
Within such a layered context, this article focuses on coastal flood hazard research challenges and opportunities as they manifest in the northwest region of Alaska to expound on the statement of concern from the IPCC 2019 Special Report: “There are critical needs to better understand the efficacy and limits of strategies for reducing risk and strengthening resilience for polar ecosystems and people, including the contribution of practices and tools to contribute to climate resilient pathways" (chapter 3 , p. 276). The intent is to identify, through our perspective as Federal scientists, some key steps necessary to advance the integration of relevant multidisciplinary observations with flood modeling and infrastructure mapping to enable the co-production of new risk assessment tools that inform local community planning and improve science collaboration among Federal, state, and regional partners for enhanced prestorm preparations and post-storm recovery. To reduce risk and strengthen resilience, improved understanding about the interactions of biophysical, economic, and socio-behavioral systems in coastal regions around the world is needed, acutely so in Arctic coastal communities where some of the highest recorded rates of change have occurred (U.S. Army Corps of Engineers, 2009; Gibbs and Richmond, 2017; University of Alaska Fairbanks Institute of Northern Engineering, 2019).

\section{ARCTIC COASTAL HAZARD STATE OF KNOWLEDGE}

The Arctic region continues to experience a wide range of environmental changes that are projected to accelerate erosion and coastal flooding rates along the north and western coastline of Alaska. Akin to lower latitudes, Arctic and sub-arctic coastal flooding is primarily driven by waves, stormtides ${ }^{3}$, sea level, sediment supply, and currents; added to these drivers are sea ice, air and sea temperatures, and permafrost degradation. Waves and stormtides have increased in frequency and magnitude along much of Alaska's coast (Stopa et al., 2016; Thomson et al., 2016; Fang et al., 2017), and projections indicate continued increases (Erikson et al., 2016, 2020; Casas-Prat et al., 2018; Casas-Prat and Wang, 2020). These changes are tightly tied to large-scale atmospheric patterns, diminishing sea ice, and longer durations of open water (Barnhart et al., 2014) particularly during fall when storms are most prevalent. Since the initiation of altimeter data in 1979 and its use for measuring sea-ice concentrations, the open-water season has more than doubled along the Beaufort

Commerce, Community, and Economic Development, the Commission also developed the Catalog of Federal Programs for Alaskan Communities as a resource for rural Alaskan communities that require funding for resiliency efforts (see Denali Commission, 2018). In addition, the State of Alaska Division of Community and Regional Affairs works to broaden its assistance to at-risk Alaska Native villages by providing hazard risk assessments and planning assistance through the Federal Emergency Management Agency (FEMA) Risk Mapping, Assessment and Planning (Risk MAP) Program. While FEMA is responsible for the overall administration of the Risk MAP program, reducing risk to flooding and hazards is a responsibility shared across multiple agencies, so broad coordination, collaboration, and consistency has become an essential component for steady success.

3 "Stormtides" is a term increasingly used to refer to water level variations due to astronomical tides and non-tidal residuals, e.g., wind-driven setup. and Chukchi Alaskan coasts (Farquharson et al., 2018; Rolph et al., 2018) and is expected to continue to increase (Wang and Overland, 2015; Crawford et al., 2021). The lengthening of the open-water season into the stormy autumn season (Barnhart et al., 2016; Box, 2019), in combination with increasing storm frequency in some areas, has resulted in more energetic and frequent waves and elevated water levels responsible for flooding and erosion (Farquharson et al., 2018; University of Alaska Fairbanks Institute of Northern Engineering, 2019; Thoman et al., 2020).

Coastal flooding is further exacerbated by vertical subsidence, lateral erosion, and collapse of permafrost-laden shores, all of which are driven by increased cumulative wave energy, elevated water levels, and warmer sea and air temperatures that directly act to thaw and destabilize otherwise frozen ground (Alaska Division of Homeland Security Emergency Management, 2018; Thoman et al., 2020). The combined effects of overland flooding, thawing permafrost, and erosion, together described in Alaska by the borrowed Yupik word "usteq," is gaining traction as a unique threat to high-latitude coasts (University of Alaska Fairbanks Institute of Northern Engineering, 2019; Bronen et al., 2020). Long-term, decadal-scale (ca. 1940s to ca. 2010s) rates of shoreline change average $-1.4 \mathrm{~m}$ per year $(\mathrm{m} / \mathrm{yr})$ (range-18.6 to $+10.9 \mathrm{~m} / \mathrm{yr}$ ) for the Beaufort and Chukchi coasts, but rates of change along the Beaufort Sea coast are nearly 6 times higher $(-1.7 \mathrm{~m} / \mathrm{yr})$ than along the Chukchi Sea coast (-0.3 m/yr) (Gibbs and Richmond, 2017; Gibbs et al., 2019). While restricted to distinct sections of the Alaska north coast, maximum erosion rates $(18.6 \mathrm{~m} / \mathrm{yr})$ are some of the highest in the world. Observations show that rates of coastal change have been increasing since at least the beginning of the 2000s at key observation sites where long-term records exist (Jones et al., 2020). Rates of shoreline change for western Alaska are still under analysis ${ }^{4}$.

Flood hazards are additionally compounded by regionally changing relative sea levels (Sweet et al., 2017). Relative sea level rise (rSLR), understood as the net effect of vertical land motion and sea level changes at a particular location, is decreasing along the southern shores of Alaska but increasing at a rate of $\sim 3.2 \pm 1.5-3.9 \pm 2.7 \mathrm{~mm} / \mathrm{yr}$ along the north and west coasts, respectively (National Oceanographic and Atmospheric Administration (NOAA), 2021; Figure 1). These rates are $~ 50 \%$ higher than the global average $(2.1 \mathrm{~mm} / \mathrm{yr})$ (Sweet et al., 2017). When modeled to forecast conditions under "business-as-usual" global scenarios, relative sea level is projected to increase from 0.3 to $3 \mathrm{~m}$ ( 1 to $10 \mathrm{ft}$ ) across northern and western Alaska by 2100 (Sweet et al., 2017). However, because measurements exceeding 30 years remain sparse for Alaska, the range of uncertainty is also large.

The strong dependency of coastal hazards on these environmental drivers, in combination with the poor spatial extent and quality (until recently) of available wave and water level time-series data, point to the need for better hindcasting

\footnotetext{
${ }^{4}$ See recently collected data available at USGS website "Modeling Western Alaska Coastal Hazards,"https://www.sciencebase.gov/catalog/item/ 5046182ce4b0241d49d62b9b.
} 

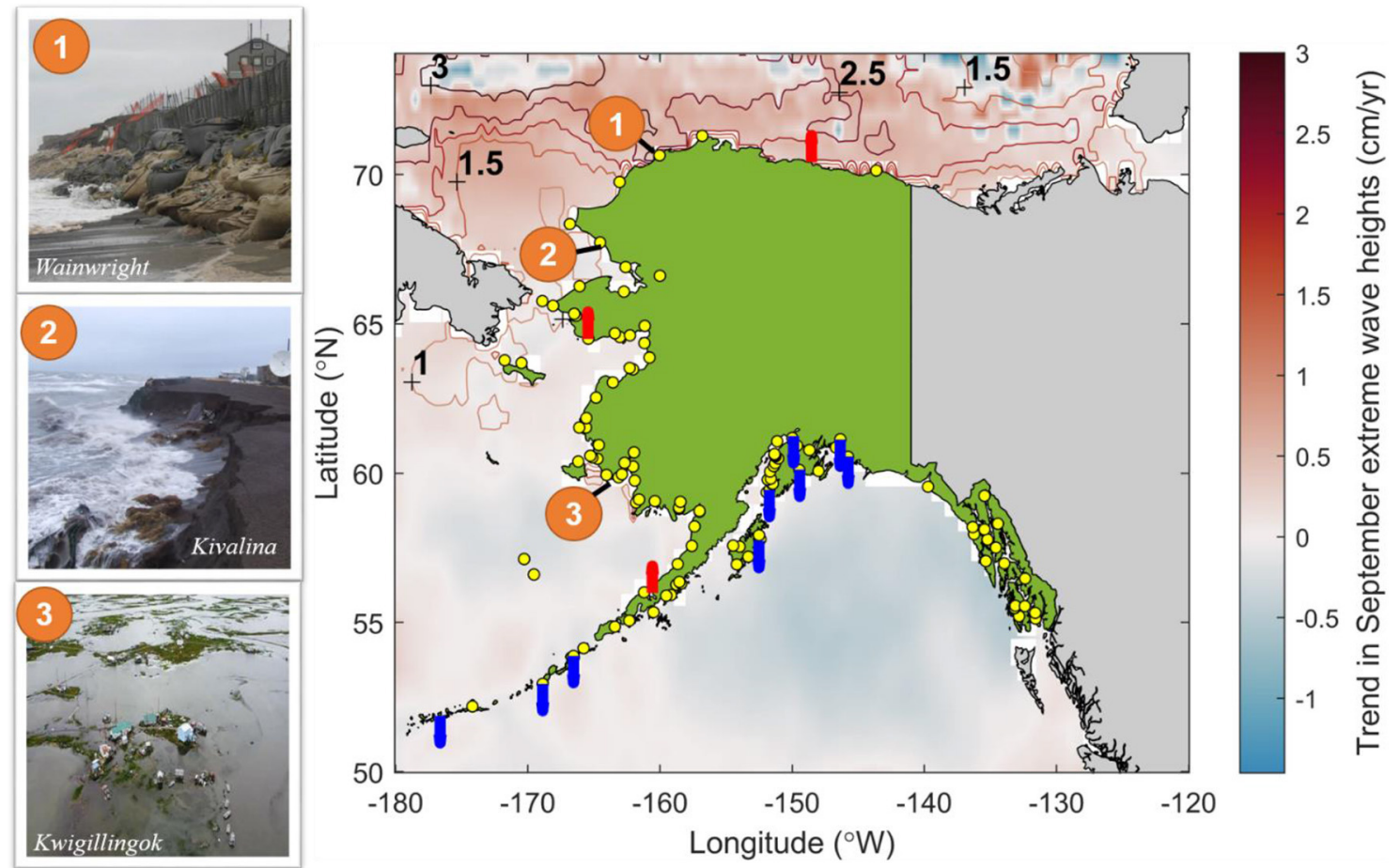

FIGURE 1 | Observed environmental changes affecting coastal flood hazards in Alaska. Sea level trends (red and blue colored arrows denoting rising and falling relative sea levels, respectively; National Oceanographic and Atmospheric Administration (NOAA), 2021), trend in annual duration of open water when the coast is exposed to storm surge and waves (contours, days/yr), and trend in 99th percentile wave heights (color scale) during the month of September (typically lowest annual sea ice extent). Wave height and open water duration trends were computed over the 35-year satellite era (1985-2019) with ERA5 reanalysis data (Hersbach et al., 2018). Sea level trends are based on tide gauge records ranging from 28 to 68 years depending on the particular location.

(modeling of past conditions) of these forcing variables. To that end, great advancements continue to occur in understanding time variability in sea ice extents, as well as wave climates and water levels, in large part due to significant strides in global-scale and regional Arctic models that account for global atmospheric and oceanic teleconnection patterns and provide reanalysis products derived from satellite data (Eyring et al., 2016). Arctic-wide and regional-scale wave climatology, developed from satellite altimeter measurements or modeled with highresolution wind-fields and new formulations that describe sea ice interactions and air-sea temperature differentialswhich contribute to wave energy growth, dissipation, and propagation-are now available and subject to further research and development (Rogers, 2019). Similarly, advancements have been made in drag formulations for proper simulation of water level variations (surge) in icy conditions (Joyce et al., 2019).

Still problematic, however, is correlating flood hazards with observed and hindcasted changes in relevant environmental forcing variables (such as the duration of the ice-free season, warming permafrost, air and ocean temperatures, changes in wave intensity and direction, and water levels) because of limited local observational data (e.g., marked flood extents and bathymetry) and poor geodetic infrastructure (Alaska Mapping Executive Committee, 2020). Priority baseline data that are lacking but needed for flood hazard modeling of individual communities include nearshore bathymetry, water level variations due to tides and storm surge, fine resolution $(\sim 5 \times 5 \mathrm{~m})$ land elevations, and critical infrastructure footprints and elevations. For many Alaska communities, the only information available to validate models is found in historical records and disaster declarations or determined from anecdotal information of physical evidence such as wrack lines (Rosales et al., 2021). Ongoing efforts, for example, by the Alaska Geological \& Geophysical Surveys (DGGS), aim to build validation data repositories of known floods at individual communities by compiling and documenting written and oral accounts, photographs, and aerial imagery (dggs.alaska.gov/hazard/coastal/flood-assessment.html). While such information is crucial to model development and validation, flood hazard studies would benefit from a deeper understanding of site-specific conditions that are known and understood by local residents, passed down from one generation to another. Examples include incident directions of storm paths that result in flooding and erosion, intervention actions taken by local residents to reroute flooding, and identification of specific areas of cultural significance that need protecting.

In light of the relatively sparse database of local knowledge and long-term observational flood hazard data, the 2019 Denali Commission Statewide Threat Assessment asserted that collecting baseline data and completing site-specific 
risk assessments is a top statewide priority to facilitate the development and implementation of pre-disaster mitigation solutions. Toward that end, the assessment included prototype scopes of work that could be followed by individual communities to determine their specific vulnerabilities. The scope of work states an explicit objective: "Both site-specific analysis of historical flood magnitude and frequency as well as modeling of future conditions are necessary for understanding flood risk and to inform long-term community decision making regarding flood mitigation, managed retreat, and/or relocation" (University of Alaska Fairbanks Institute of Northern Engineering, 2019, Appendix B-1). Yet the clear admonition to focus first on collection of historical flood and storm data reaffirms the direction previously adopted by the state of Alaska in its coastal monitoring build-out plan (e.g., see Alaska Mapping Executive Committee, 2018; Overbeck, 2018).

The scarcity of long-term observational data in Alaska raises an important consideration for the immediate redirection of adaptation planning. The choices are to (1) wait for a larger database of updated bathymetry and past and present flood and storm data before proceeding with model projections of plausible future scenarios or (2) make best estimates using state-of-theart methods and data. Although collection of baseline, historical, and indigenous knowledge data are needed for model calibration and validation of past events that in turn will likely allow for higher accuracy of model projections, environmental changes are well-underway and preparation and planning for coastal hazards is needed now. Furthermore, decadal-long projections of environmental forcing variables have substantial variability and uncertainty, requiring the consideration of multi-model ensemble results. Thus, while some degree of compounding uncertainty arises from a lack of highly accurate input and validation data, for example, with the combination of incomplete nearshore bathymetry and projected storm surge that might occur 10 to 30 years from now, the variability in storm surge from different projection models is likely greater than the error introduced by the use of incomplete or outdated nearshore bathymetry (Weaver and Slinn, 2010; Barnard et al., 2019; Hinkel et al., 2021; Toimil et al., 2021).

Development of model scenario projections that estimate flood hazard in parallel with ongoing data collection as outlined by the Alaska state threat assessment could be updated as new data and information become available. Using currently available state-of-the-art models and data combined with transparent and well-documented uncertainty ranges, coastal hazard projections may be made (for example, by including an ensemble of projected flood hazards) and used for immediate community-based adaptation planning. Below, we discuss a specific dynamic model system that Arctic communities could use to simulate plausible flood hazards for the near-term planning horizon (2020-2050).

\section{DISCUSSION: PROSPECTIVE ON MODELING OF FUTURE FLOOD HAZARDS}

The net result of the cumulative environmental changes underway in the Arctic is a highly dynamic circumstance that is not typically captured by existing flood forecast models, premised as they are on historical flood frequency data. That is, environmental forcings responsible for coastal flooding and erosion are influenced by global-scale atmospheric and oceanic teleconnection patterns that respond non-linearly to a changing climate (Reguero et al., 2019); thus, reliance on past observations may not represent future conditions in Alaska. Global climate models (GCMs) are the best tools for understanding and projecting complex dynamics of the climate system-i.e., how patterns of the atmosphere, ocean, land, and sea ice will evolve under current and projected greenhouse gas and aerosol emissions (Flato et al., 2013). GCMs are now routinely used for assessing climatological parameters, including changes in storm patterns, atmospheric variability, temperatures, and precipitation. However, GCM products are still rather coarse $\left(\geq 0.25^{\circ}\right)$ and do not directly include wave and stormtide data, necessitating independent modeling of these variables, downscaling to the nearshore, and simulating overland flow using site specific elevation data.

To date, only a few studies have attempted to identify future flood hazards using projected changes in sea ice and oceanographic conditions, and those remain limited in geographic scope (Casas-Prat and Wang, 2020; Erikson et al., 2020). Until recently, the majority of scientific efforts to characterize potential coastal impacts of climate change have focused primarily on long-term sea level rise with a static tide level (e.g., Hauer et al., 2016; Overbeck et al., 2020; Buzard et al., 2021a,b) and have not comprehensively accounted for dynamic physical drivers such as tidal non-linearity, storms, short-term climate variability, erosion, and consequent flooding response. In contrast, the Coastal Storm Modeling System (CoSMoS) is designed to assess future coastal flooding exposure by integrating sea level rise, dynamic water levels, and coastal change (Erikson et al., 2018; O’Neill et al., 2018; Barnard et al., 2019). CoSMoS is a physics-based numerical modeling approach that downscales available GCM data to project future coastal hazards to the midand late-Twenty-first century under different climate scenarios.

CoSMoS is a dynamic modeling approach designed to achieve detailed predictions of coastal flooding due to future sea-level rise and extreme storm events in a way that can be integrated with long-term coastal evolution over large geographic areas (Barnard et al., 2019). CoSMoS employs a predominantly deterministic approach to make detailed predictions $(10 \mathrm{~m})$ of storm-induced coastal flooding over large geographic scales (hundreds of kilometers). Tides, waves, and storm surge are dynamically downscaled using a series of nested models, which are then scaled further to fit local flood projections so they can be used in community-level coastal planning. Rather than relying on historical storm records (which has been the norm until now), CoSMoS uses wind, atmospheric pressure, and sea ice projections from the latest available global climate models to forecast coastal storm scenarios under changing climatic conditions over the coming decades. A prototype CoSMoS was first developed for California (Barnard et al., 2014); model system variants that meet specific local needs are being developed for the U.S. East Coast, Pacific Northwest, and Pacific Islands (e.g., Storlazzi et al., 2021). Adapting the model system to Alaska aims to focus on Alaska 


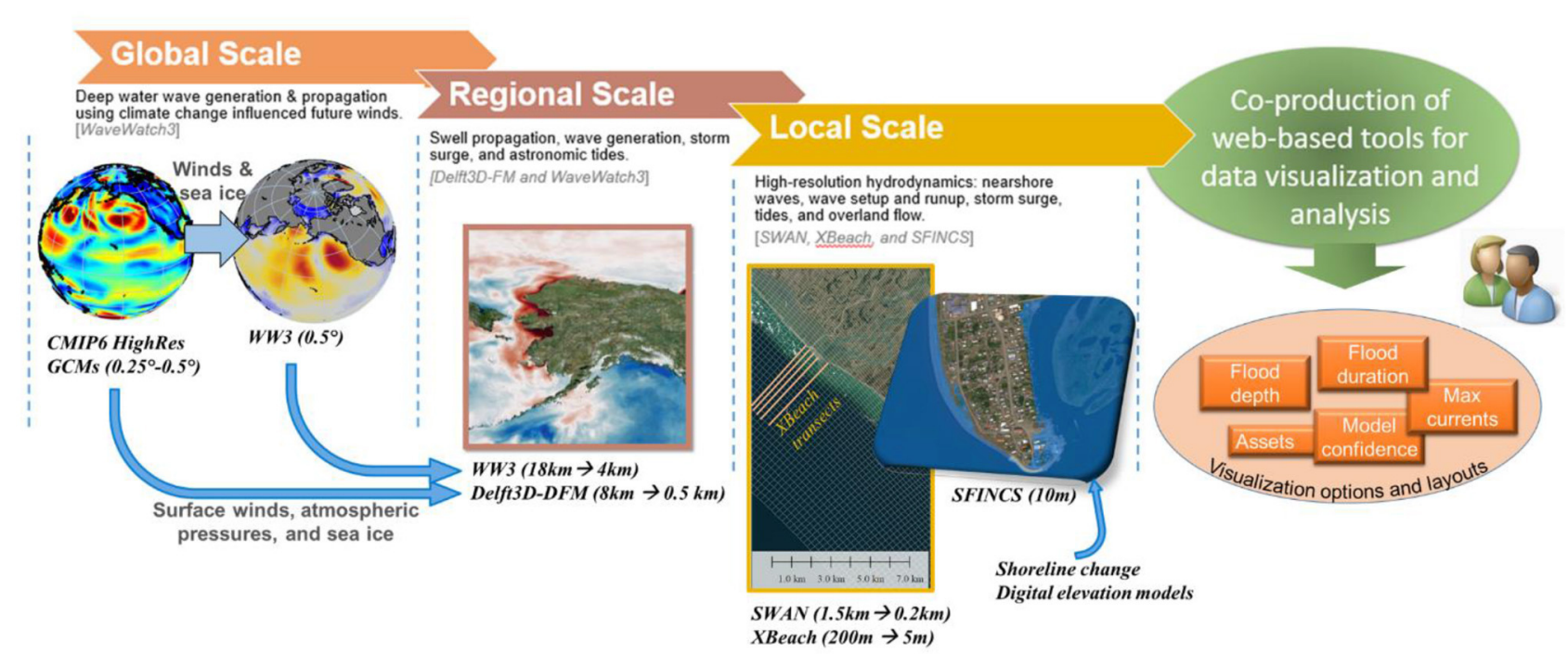

FIGURE 2 | Schematic overview of model system and development of hazard assessment products. The model train downscales projected atmosphere and sea ice fields from global climate models to regional and local scale oceanographic and flood hazards. At the local scale, historical long-term shoreline erosion is incorporated into the digital elevation models that are used to populate the overland flow models. In collaboration with stakeholders, model results are translated to digital tools aimed at assessing flood hazards and vulnerabilities.

Native communities along the Bering and Chukchi Sea coastlines where storm threats are high.

The buildout of CoSMoS for Alaska involves the use of atmospheric outputs (winds, sea level pressures, and precipitation) and sea ice from the highest resolution $(25-50 \mathrm{~km})$ as well as the most recent generation of GCMs that contributed to the 6th generation Coupled Model Intercomparison Project (CMIP6) (Eyring et al., 2016). The GCM models are part of the High Resolution Model Intercomparison Project (HighResMIP), a widely endorsed study that seeks to improve GCM modeling and applies a systematic approach to investigate the impact of horizontal resolution on simulating climate variables (Haarsma et al., 2016) $)^{5}$.

The CoSMoS-Alaska model system comprises a global scale wave model (WaveWatchIII) with nested grids specific to the Alaska coastline, a series of local nested coastal wave models (SWAN and XBeach) for computation of wave setup and runup at the shore, a regional flexible mesh hydrodynamic model (Delft3D-FM) for computation of storm surge, and an overland flow model (SFINCS, Leijnse et al., 2021) that includes infiltration and compound flooding from fluvial discharges when relevant (Figure 2). The overland flow models are populated with recently acquired 2-m or better digital elevation models (2010-2019). Continuous time series of nearshore waves and storm surge are developed but overland flood simulations are limited to times when surge or waves are present as a means to reduce

\footnotetext{
${ }^{5}$ At the time of initiating the expansion to Alaska in 2021, HighResMip products remain limited to the RCP8.5 climate scenario and limited to the projected time-period covering 2020-2050. Lower emission scenarios (e.g., RCP4.5 and/or RCP2.6) are anticipated. The RCP4.5 and RCP8.5 scenarios characterize medium stabilizing and high radiative forcing scenarios, respectively, and that they are roughly equivalent out to 2050 .
}

computational costs (Figure 2). All storm events are run in combination with discrete sea level states ranging from 0 to $3 \mathrm{~m}$ at $0.5-\mathrm{m}$ increments to encompass all plausible combinations of future storms and SLR. Because scientific consensus on the magnitude of SLR projections is constantly evolving, SLR and its compound effect with coastal storms is characterized by running all combinations of storms and SLR increments, independent of time. Flood maps of discrete annual exceedance probabilities (10, 5,2 , and $1 \%$ ) are then calculated from the overland flood model on a per-grid cell basis.

Variability in GCM projections is addressed by applying four different GCMs and computing the ensemble mean. Due to the nature of generating decadal long forecasts, uncertainty related to the GCMs is approached from a historical climatological perspective by comparing historical GCM runs with observed regional scale patterns. Uncertainty in the projected flood maps is quantified by the quadrature sum of root-mean-square differences between modeled and observed wave heights, water levels, and the digital elevation model. Because of the temporal and spatial sparsity of observation data, comparisons between modeled and observed nearshore conditions are not possible at all communities. For those situations where no observational nearshore water level or wave data or overland flood data are yet available for model validation, estimated uncertainties can be assumed from other regional locations and emphasized during engagement with stakeholders. As already mentioned, when new data are collected, particularly data that can be used for flood extent validation, the established model train can be rerun for those overlapping time periods to assess model accuracy and adjust uncertainty maps if needed. Resulting model projections include flood extent, depth, duration, uncertainty, water elevation, wave runup, maximum wave height, and maximum 
current velocity. To assess the potential socioeconomic impacts and communicate the corresponding risks and vulnerabilities associated with site-specific coastal change and flood hazards, the data can be made available on publicly accessible web tools co-developed with individual community stakeholders, as well as state and Federal stakeholders.

\section{DISCUSSION: CO-PRODUCTION OF ASSESSMENT TOOLS}

While many scientists and projects are attentive to the flood hazard problem in Alaska, there are still very limited coastal flood hazard vulnerability assessment tools that use cutting edge modeling approaches and yet can be customized to meet specific community information needs in a manner that can readily support local adaptation planning. By some reports, more than 3,500 tools and resources from more than 80 organizations in circulation have been designed to support some form of climate adaptation planning (Nordgren et al., 2016), with over 200 readily available in the U.S. (Tuler et al., 2020). Yet because of the scope and urgency of the climate challenge for many communities, the scale of planning remains insufficient and needs adjustment. Even when communities develop climate mitigation, adaptation, or resilience plans, they generally neglect to identify specific goals or calculate the relevant costs of either implementation or inaction (Meerow and Woodruff, 2020). Given the frequent limitations in local capacity and technical tools to support adaptation planning, there is a corresponding need for improved co-production process, by which we mean the concept of active engagement among multiple interested parties (scientists, residents, policy makers) to produce multiple new social outcomes, including advancement of knowledge, improved decision-making, and greater social equity (e.g., see Miller and Wyborn, 2020). As the science of numerical modeling improves, we anticipate corresponding refinements in advancing an efficient approach to inform and co-produce locally customized flood hazard maps to support culturally appropriate and cost-effective adaptation strategies, pairing flood hazard modeling output data with stream-lined community engagement processes to ascertain the priority tools and deliverables deemed most relevant for local use.

Each community is unique due to the specific features of local geology, hydrology, community layout, ecosystem services, and many other factors. Consequently, all hazard and vulnerability assessment tools ought to be tailored to each specific community. In Alaska, where subsistence hunting and gathering activities are critical features of survival and cultural identity among Native peoples, more work is needed to determine what flood hazard vulnerability really means for each Alaska community, and what specific geospatial products and tools can most efficiently facilitate optimal local use in culturally appropriate ways. These topics remain fertile areas for research in the social sciences. For example, researchers (Brady and Leichenko, 2020) recently documented coastal hazard impacts that reach beyond the familiar municipal infrastructure of collapsed roads, runways, and buildings to diminish quality of life in other ways for many
Native residents of Alaska's North Slope Borough. They found that residents report increasing damage or loss of community assets that are important to the subsistence economy, such as unusable hunting camps and ice cellars previously used to store harvested meat, and sudden coastline changes that imperil boat crews and undermine confidence in marine navigation systems. The authors also report growing local concern about potential contaminant exposure from eroding Distant Early Warning (DEW) radar sites and concerns expressed about the lost revenues associated with reduced leasing opportunities on Alaska Native corporation lands (2020: 266-270). Earlier research (e.g., Kofinas et al., 2010) has previously documented other concerns related to accessing subsistence foods, such as reduction in habitat for walrus and ice seals; increased safety hazards posed to hunters by thinner and less stable sea and river ice; and increased cost of living because of unreliable barge delivery of fuel and supplies as a result of changing river discharge. Such expressions of community concern exemplify the importance of customized bidirectional information flows among technical experts and local stakeholders.

Mounting research indicates that deliberative planning approaches developed through co-production can in fact improve local adaptive capacities and improve the effectiveness of modeling tools for community use. For example, one prominent approach gaining momentum over the last decade is the Vulnerability, Consequences, and Adaptation Planning Scenarios (VCAPS) process, which was explicitly designed to facilitate stakeholder collaboration and co-production of knowledge as communities assess their climate risks and develop strategies to manage them through the lens of various change scenarios (Webler et al., 2016).

The VCAPS process was pioneered in 2014 by the Social and Environmental Research Institute and the Carolinas Integrated Sciences and Assessments Program. It follows standard participatory modeling techniques in community settings through a facilitated conversation that produces scenarios, represented by diagrams, linking climate and weather changes to local consequences. The process can be implemented in a single day workshop, but works best through a series of meetings that involves local resident experts and a multi-person team comprising a facilitator, scientific expert(s), diagramming scribe, and notetaker. Discussions are informed both by best available science and by local knowledge and community preferences. The process can be augmented by use of communitybased data collection and change detection, such as modeled by the BeringWatch Indigenous Sentinel Network-an internetbased system pioneered by the Aleut Community of St. Paul Island that facilitates monitoring efforts in Alaska Native villages by Tribal employees, contractors, and local volunteers. The network operates through a suite of mobile data collection apps to establish an online database augmented through training materials and social media communication tools. Following a recent assessment of measurable performance outcomes, the VCAPS approach demonstrated success as one viable model for how analysis and deliberation can be synthesized in a productive manner (Tuler et al., 2020). With specific regard to potential development of water management decision support tools, the 
path of interactive co-production has also proven capable of adding substantial value, especially in efforts to quantify and resolve modeling uncertainty to achieve more credible and robust outcomes (e.g., see Basco-Carrera et al., 2017; Barnhart et al., 2018).

To be sure, the merits of co-production in situations that involve both scientists and holders of indigenous knowledge are already prominent themes in Arctic research, and very much a focal topic in Alaska. Among Federal scientists, there is now broad recognition of the need to engage with Native communities in a more meaningful and productive way (e.g., U.S. Interagency Arctic Research Policy Committee, 2018; Protection of the Arctic Marine Environment Arctic Council, 2019), while a steady flow of published literature persistently evaluates the efficacy of status quo procedures and raises expectations about the normative standards and future possibilities of co-production (e.g., Pulsifer et al., 2018; Wheeler et al., 2020). The reality is that researchers continue on a global scale to experiment with methods and tools to enhance the efficacy of co-production (Wyborn et al., 2019). However, the serious challenge remains that proper experimentation and honorable pursuit of the potential of co-production will also require honest recognition of its current manifest limitations and emergent constructive criticisms (e.g., Enriques-de-Salamanca, 2018; Lemos et al., 2018; Goodwin, 2019; Oliver et al., 2019). Scientists, indigenous knowledge holders, and community residents can all take constructive steps to advance the long-term work still needed to achieve full actualization of healthy co-production. A few examples may help to illustrate relevant social dynamics in Alaska that underscore the need for more refinement.

For decades, the U.S. government has aspired to integrate indigenous knowledge more thoroughly with institutional scientific knowledge production, but those expectations multiply without authoritative guidance or consistent mechanisms in place to make it happen. For example, in October 2019, the National Science Foundation (NSF) initiated the Navigating the New Arctic (NNA) program with its first round of grants totaling $\$ 37.5$ million, essentially doubling the amount NSF spends on Arctic research with the explicit goal of encouraging scientists to enlist Indigenous communities in more direct co-production by involving them in planning and executing field projects. But most indigenous communities do not have the administrative infrastructure support required to submit a competitive proposal to NSF, so the good intention to expand co-production opportunities actually stimulated greater frustration on the part of local communities. "We continue to lack meaningful access and voice in the vast landscape that is the research process," wrote a consortium of 20 tribes in the Bering Strait region in a broadly circulated complaint to NSF and other research groups operating in Alaska (Stone, 2020, p. 1,284). Indigenous leaders prepared a long list of recommendations, including the suggestion for NSF to focus more on projects that address the sustainability of Arctic communities, like food security and infrastructure, and to set aside $25 \%$ of NNA funds for indigenous-led projects. The letter explicitly recommended that projects aiming to address impacts to infrastructure focus on site-specific risk assessments that enable communities to develop informed solutions (Stone, 2020).
The urgency of more direct and equitable co-production has become even more acute in 2021 as the Interagency Arctic Research Policy Committee (IARPC), involving leaders from 16 agencies, departments, and offices across the Federal government, works to complete details on the forthcoming 2022-2026 Arctic Research Plan. That plan identifies coproduction and "Indigenous leadership in research" as one of five foundational activities to be addressed by all priority research areas and seeks to establish new standards of guidance and mechanisms to address Native concerns. The plan builds on the premise that a fertile foundation of collaboration already exists between Federal science agencies and universities with Alaska Native communities that would justify the timely launch of a new regional initiative to promote a larger role for Alaska Native communities in the co-production of Arctic science. The effort would presumably reap benefits for social justice as well as climate science, public health, hazard mitigation, and environmental stewardship. Under the priorities of the Biden White House, the work to achieve these visionary goals has accelerated (e.g., see https:// www.whitehouse.gov/priorities), yet the immediate challenge remains how to advance them while working within the existing legal, institutional, and ethical framework of the Federal government.

Social science literature routinely draws attention to potential tensions that may arise between research interests that are accountable first to decision-makers and agency mission, on one hand, and research interests that place accountability elsewhere and actively aim to challenge the status quo (e.g., see Wyborn et al., 2019). Within the context of co-production, there are many important social goals and responsibilities that scientists should consider beyond what pleases a specific community of stakeholders on a particular topic, including what can be validated as reliable and non-biased information. These weightof-evidence considerations have real-world implications. For example, the U.S. Coastal Zone Management Program was originally created to allow for consistency review between Federal and state environmental protections. But in Alaska, when the state program came up for renewal in 2011, public concern over "traditional [indigenous] knowledge" weight-ofevidence procedures led to legislative stalemates that eliminated the entire program. An attempt to develop a standardized weight-of-evidence approach proved non-consensual, so the program reauthorization collapsed by one vote. Many of those legislators voting no were concerned over misuse of "local veto" opportunities, primarily because of poorly defined procedures over how to balance potential contradictions between indigenous knowledge and science. Thus, because of avoidable validation concerns, the State ended a functional program through which local community issues gained traction in Federal decisions (see SitNews, 2011).

Moving forward, a few core summary concepts seem likely to promote the promise of constructive co-production without compromising the needed consensual support to achieve improved output and better outcomes. Scientists need to enhance indigenous participation in coastal hazard research and adaptation planning by engaging communities and their representatives in the design of useful hazard assessment tools 
and solutions that directly help communities achieve their goals. Indigenous communities need to help establish mechanisms to ensure that participants' voices are fully representative of their constituents. Scientists and indigenous communities both need to promote an environment of mutual respect for multiple ways of knowing. Scientists need to better accommodate cultural sensitivities and local social realities, while indigenous communities need to recognize the obligations of Federal scientists and the proper role for validation concerns without preemptive accusations of cultural disrespect. Federal scientists have discrete ethical and legal constraints around science integrity that may not always comport with more unilateral approaches advocated by Native groups or adopted by private academic researchers. It will ultimately require a deeper and more substantive social relationship between scientists and community members to bring the desired adaptive planning tools and products into practice.

\section{SUMMARY AND FINAL THOUGHTS}

Due to a combination of rising sea level, diminished sea ice, rising temperatures, and several other climate change related environmental conditions, many of Alaska's Arctic and subarctic coastal communities are under severe threat of flooding and erosion. The physical hazards are compounded by social and economic challenges, which continue to impede viable options for local mitigation and adaptation responses. Alaska village populations are generally small, geographically isolated, may lack the technical expertise and staffing to protect existing infrastructure, and rarely maintain backup facilities or reserve utilities in the event of failure. The combination of low population density and high mitigation expense creates an economic cost-benefit calculus that generally disqualifies these communities from mainstream disaster assistance programs. Additionally, mapping coastal hazards has received little attention due in part to the lack of robust long-term observation data that are typically used to support development of coastal models. Downscaling methods of global climate models to regional and local scales are now sufficiently robust that decisions

\section{REFERENCES}

Alaska Division of Homeland Security and Emergency Management (2018). Alaska State Hazard Mitigation Plan. Juneau: Alaska Dept of Military and Veterans Affairs Division of Homeland Security and Emergency Mgmt, 754. Available online at: https://www.commerce.alaska.gov/dcra/DCRARepoExt/ RepoPubs/Plans/2018\%20SHMP_Blue\%2010-15-18.pdf

Alaska Mapping Executive Committee (2018). "2018 Alaska coastal mapping summit summary report," in Alaska Mapping Executive Committee, ed M. Kumle (Anchorage: Alaska Ocean Observing System \& State of Alaska Department of Natural Resources).

Alaska Mapping Executive Committee (2020). Mapping the Coast of Alaska. A 10-Year Strategy in Suppot of the United States Economy, Security, and Environment. Washington, DC: AMEC; National Oceanic and Atmospheric Administration and the U.S. Geological Survey.

Barnard, P. L., Erikson, L. H., Foxgrover, A. C., Hart, J. A. F., Limber, P., O'neill, A. C., et al. (2019). Dynamic flood modeling essential to assess the coastal impacts of climate change. Sci. Rep. 9:4309. doi: 10.1038/s41598-019-40742-z about flooding hazards within the planning horizon (through 2050) can be made. However, transparent and well-documented uncertainties should be updated when possible and most importantly, clearly communicated and incorporated into community-level adaptation planning. To achieve adaptation strategies that are viable and more likely to succeed, model results that show future hazard estimates need to be developed jointly with stakeholders, pairing flood hazard modeling output data with streamlined community engagement and co-production processes to ascertain the priority tools and deliverables most relevant for public use. In this manner, Arctic scientists have a vital role to play in advancing a more integrated and service-oriented approach to community resilience planning that can be promoted on a national scale.

The American Arctic region seems poised at a significant historic crossroads. What Arctic decision-makers and scientists once construed primarily as straightforward environmental engineering challenges have been increasingly revealed as a complex multi-stakeholder negotiation, with complicated narratives. That circumstance creates a rather important role for Arctic scientists and indigenous knowledge experts to find a way to move forward collectively. It calls to mind the stirring words of a prominent Alaska Native leader who once memorably admonished an audience of Arctic scientists, "Your involvement ... can help to save a proud and ancient American culture. If that's not enough to get you focused on your work, I don't know what is!" (Itta, 2011). Indeed, a crucial moment in the history of Arctic America is upon us. Hopefully, the consortium of Alaska Natives, scientists, and policy makers can rise to the occasion.

\section{AUTHOR CONTRIBUTIONS}

All authors listed have made a substantial, direct, and intellectual contribution to the work and approved it for publication.

\section{FUNDING}

DW was funded by the USGS Alaska Regional Office. LE was funded by the USGS Coastal and Marine Geology Program. for predicting the impact of storms on high-energy, active-margin coasts. Nat. Hazards 74, 1095-1125. doi: 10.1007/s11069-014-1236-y

Barnhart, B. L., Golden, H. E., Kasprzyk, J. R., Pauer, J. J., Jone, S., C. E., Sawicz, K. A., et al. (2018). Embedding co-production and addressing uncertainty in watershed modeling decision-support tools: successes and challenges. Environ. Model Softw. 109, 368-378. doi: 10.1016/j.envsoft.2018.08.025

Barnhart, K. R., Miller, C. R., Overeem, I., and Kay, J. E. (2016). Mapping the future expansion of Arctic open water. Nat. Clim. Change 6, 280-285. doi: $10.1038 /$ nclimate 2848

Barnhart, K. R., Overeem, I., and Anderson, R. S. (2014). The effect of changing sea ice on the physical vulnerability of Arctic coasts. Cryosphere 8, 1777-1799. doi: 10.5194/tc-8-1777-2014

Basco-Carrera, L., Van Beek, E., Jonoski, A., Benítez-Ávila, C., and Pj Guntoro, F. X. (2017). Collaborative modelling for informed decision making and inclusive water development. Water Resourc. Manage. 31, 2611-2625. doi: $10.1007 / \mathrm{s} 11269-017-1647-0$ 
Berman, M., and Schmidt, J. (2019). Economic effects of climate change in Alaska. Weather Clim. Soc. 11, 245-258. doi: 10.1175/WCAS-D-18-0056.1

Box, J. E. (2019). Key indicators of Arctic climate change: 1971-2017. Environ. Res. Lett. 14:18. doi: 10.1088/1748-9326/aafc1b

Brady, M. B., and Leichenko, R. (2020). The impacts of coastal erosion on Alaska's North Slope communities: a co-production assessment of land use damages and risks. Polar Geogr. 43, 259-279. doi: 10.1080/1088937X.2020.1755907

Bronen, R., and Chapin, F. S. (2013). Adaptive governance and institutional strategies for climate-induced community relocations in Alaska. Proc. Nat. Acad. Sci. U.S.A. 110, 9320-9325. doi: 10.1073/pnas.1210508110

Bronen, R., Pollock, D., Overbeck, J., Stevens, D., Natali, S., and Maio, C. (2020). Usteq: Integrating indigenous knowledge and social and physical sciences to coproduce knowledge and support community-based adaptation. Polar Geogr. 43, 188-205. doi: 10.1080/1088937X.2019.1679271

Buzard, R. M., Overbeck, J. R., Chriest, J., Endres, K. L., and Plumb, E. W. (2021a). Coastal Flood Impact Assessments for Alaska Communities. Anchorage, AK: Alaska Division of Geological \& Geophysical Surveys Report of Investigation 2021-1. doi: 10.14509/30573

Buzard, R. M., Overbeck, J. R., and Miller, K. Y. (2021b). "Coastal flood impact assessments for Alaska communities: Nunam Iqua," in Coastal flood impact assessments for Alaska communities: Alaska Division of Geological \& Geophysical Surveys Report of Investigation 2021-1A, eds R. M. Buzard, J. R. Overbeck, C. Jonathan, K. L. Endres, and E. W. Plumb (Anchorage, AK). doi: $10.14509 / 30675$

Casas-Prat, M., and Wang, X. L. (2020). Projections of extreme ocean waves in the Arctic and potential implications for coastal inundation and erosion. J. Geophys. Res. Oceans 125:e2019JC015745. doi: 10.1029/2019JC015745

Casas-Prat, M., Wang, X. L., and Swart, N. (2018). CMIP5-based global wave climate projections including the entire Arctic ocean. Ocean Model. 123, 66-85. doi: 10.1016/j.ocemod.2017.12.003

Crawford, A., Stroeve, J., Smith, A., and Jahn, A. (2021). Arctic open-water periods are projected to lengthen dramatically by 2100. Commun. Earth Environ. 2:10. doi: $10.1038 / s 43247-021-00183-\mathrm{x}$

Denali Commission (2018). Community Resilience in Alaskan Communities Catalog of Federal Programs. Available online at: https://www.denali.gov/ wp-content/uploads/2018/10/Catalog-of-Federal-Programs-for-AlaskanCommunities-27Jul2018- Final.pdf (accessed June 24, 2021).

Enriques-de-Salamanca, A. (2018). Stakeholders' manipulation of environmental impact assessment. Environ. Impact Assess. Rev. 68, 10-18.. doi: 10.1016/j.eiar.2017.10.003

Erikson, L. H., Barnard, P. L., O'Neill, A. C., Wood, N., Jones, J., Finzi-Hart, J., et al. (2018). Projected $21^{\text {st }}$ century coastal flooding in the southern california bight. Part 2: tools for assessing climate change driven coastal hazards and socio-economic impacts. J. Mar. Sci. Eng. 6:76. doi: 10.3390/jmse6030076

Erikson, L. H., Gibbs, A. E., Richmond, B. M., Storlazzi, C. D., Jones, B. M., and Ohman, K. A. (2020). Changing Storm Conditions in Response to Projected 21st Century Climate Change and the Potential Impact on an Arctic Barrier Island-Lagoon System-A Pilot Study for Arey Island and Lagoon, Eastern Arctic Alaska. Reston, VA: U.S. Geological Survey Open-File Report 2020-1142. doi: 10.3133/ofr20201142

Erikson, L. H., Hegermiller, C. E., Barnard, P. L., and Storlazzi, C. D. (2016). Wave Projections for United States Mainland Coasts. Reston, VA: U.S. Geological Survey summary of methods to accompany data release. doi: 10.5066/F7D798GR

Eyring, V., Bony, S., Meehl, G. A., Senior, C. A., Stevens, B., Stouffer, R. J., et al. (2016). Overview of the coupled model intercomparison project phase 6 (CMIP6) experimental design and organization. Geosci. Model Dev. 9, 1937-1958. doi: 10.5194/gmd-9-1937-2016

Fang, Y.-C., Potter, R. A., Statscewich, H., Weingartner, T. J., Winsor, P., and Irving, B. K. (2017). Surface current patterns in the northeastern Chukchi sea and their response to wind forcing. J. Geophys. Res Oceans 122, 9530-9547. doi: 10.1002/2017JC013121

Farquharson, L. M., Mann, D. H., Swanson, D. K., Jones, B. M., Buzard, R. M., and Jordan, J. W. (2018). Temporal and spatial variability in coastline response to declining sea-ice in northwest Alaska. Mar. Geol. 404, 71-83. doi: 10.1016/j.margeo.2018.07.007

Flato, G., J., Marotzke, J., Abiodun, B., Braconnot, S. C., Chou, W., Collins, P., et al. (2013). "Evaluation of climate models," in Climate Change 2013: The Physical Science Basis. Contribution of Working Group I to the Fifth Assess-ment Report of the Intergovernmental Panel on Climate Change, eds T. F. Stocker, D. Qin,
G.-K. Plattner, M. Tignor, S. K. Allen, J. Boschung, A. Nauels, Y. Xia, V. Bex, and P. M. Midgley (Cambridge; New York, NY: Cambridge University Press).

Gibbs, A. E., Nolan, M., Richmond, B. M., Snyder, A. G., and Erikson, L. H. (2019). Assessing patterns of annual change to permafrost bluffs along the North Slope coast of Alaska using high-resolution imagery and elevation models. Geomorphology 336, 152-164. doi: 10.1016/j.geomorph.2019.03.029

Gibbs, A. E., and Richmond, B. M. (2017). National Assessment of Shoreline Change-Summary Statistics for Updated Vector Shorelines and Associated Shoreline Change Data for the North Coast of Alaska, U.S.-Canadian border to Icy Cape. Reston, VA: U.S. Geological Survey Open-File Report 2017-1107. doi: $10.3133 /$ ofr 20171107

Goodwin, G. (2019). The problem and promise of coproduction: Politics, history, and autonomy. World Dev. 122, 501-513. doi: 10.1016/j.worlddev.2019.06.007

Haarsma, R. J., Roberts, M. J., Vidale, P. L., Senior, C. A., Bellucci, A., Bao, Q., et al. (2016). High resolution model intercomparison project (HighResMIP v1.0) for CMIP6. Geosci. Model Dev. 9, 4185-4208. doi: 10.5194/gmd-9-4185-2016

Hauer, M. E., Evans, J. M., and Mishra, D. R. (2016). Millions projected to be at risk from seal-level rise in the continental United States. Nat. Clim. Chang. 6, 691-695. doi: 10.1038/nclimate2961

Hersbach, H., Bell, B., Berrisford, P., Biavati, G., Horányi, A., Muñoz Sabater, J., et al. (2018). ERA5 Hourly Data on Single Levels From 1979 to Present. Copernicus Climate Change Service (C3S) Climate Data Store (CDS). doi: $10.24381 /$ cds.adbb $2 \mathrm{~d} 47$

Hinkel, J., Feyen, L., Hemer, M., Le Cozannet, G., Lincke, D., Marcos, M., et al. (2021). Uncertainty and bias in global to regional scale assessments of current and future coastal flood risk. Earth's Fut. 9:e2020EF001882. doi: $10.1029 / 2020 \mathrm{EF} 001882$

Immediate Action Work Group (2009). Recommendations to the Governor's Subcabinet on Climate Change. Available online at: https://www.denali. gov/wp-content/uploads/2018/10/Reccomendations-to-the-GovernorsSubcabinet-on-Climate-Change.pdf

Itta, E. (2011). Mayor Itta's Banquet Speech. Barrow: North Slope Science Initiative (NSSI) Workshop Report. Available online at: https://northslopescience.org/ wp-content/uploads/110329_NSSI_Barrow_Workshop_Report_FINAL.pdf (accessed June 1, 2021).

Jones, B. M., Irrgang, A. M., Farquharson, L. M., Lantuit, H., Whalen, D., Ogorodov, S., Grigoriev, M., et al. (2020). "Coastal permafrost erosion," in Arctic Report Card 2020. National Oceanic and Atmospheric Agency. Available online at: https://repository.library.noaa.gov/view/noaa/27897

Joyce, B. R., Pringle, W. J., Wirasaet, D., Westerin, J. J., Van Der Westhuysen, A. J., Grumbine, R., et al. (2019). High resolution modeling of western Alaskan tides and storm surge under varying sea ice conditions. Ocean Model. 141:101421. doi: 10.1016/j.ocemod.2019.101421

Kettle, N. M., Chase, O., O'domin, D., Roehl, and Cozzetto, K. (2019). Building Capacity for Tribal Climate Adaptation Planning in Alaska: A Post-Training Needs Assessment. Fairbanks: University of Alaska Fairbanks.

Kofinas, G. P., Chapin, F. S., Burnsilver, S., Schmidt, J. I., Fresco, N. L., Kielland, K., et al. (2010). Resilience of Athabascan subsistence systems to interior Alaska’s changing climate. Can.J. For. Res. 40, 1347-1359. doi: 10.1139/X10-108

Kousky, C., Kunreuther, H., LaCour-Little, H., and Wachter, S. (2020). Flood risk and the U.S. housing market. J. Hous. Res. 29 (Suppl. 1), S3-S24. doi: $10.1080 / 10527001.2020 .1836915$

Leijnse, T., van Ormondt, M., Nederhoff, K., and van Dongeren, A. (2021). Modeling compound flooding in coastal systems using a computationally efficient reduced-physics solver: Including fluvial, pluvial, tidal, wind- and wave-driven processes. Coastal Eng. 163:103796. doi: 10.1016/j.coastaleng.2020.103796

Lemos, M. C., Arnott, J. C., Ardoin, N. M., Baja, K., Bednarek, A. T., Dewulf, A., et al. (2018). To co-produce or not to co-produce. Nat. Sustain. 1, 722-724. doi: 10.1038/s41893-018-0191-0

Marino, E. (2012). The long history of environmental migration: Assessing vulnerability construction and obstacles to successful relocation in Shishmaref, Alaska. Glob. Environ. Change 22, 374-381. doi: 10.1016/j.gloenvcha.2011.09.016

Meerow, S., and Woodruff, S. C. (2020). Seven principles of strong climate change planning. J. Am. Plan. Assoc. 86, 39-46. doi: 10.1080/01944363.2019.1652108

Melvin, A. M., Larsen, P., Boehlert, B., Neumann, J. E., Chinowsky, P., Espinet, X., et al. (2017). Climate change damages to Alaska public infrastructure and the economics of proactive adaptation. Proc. Nat. Acad. Sci. U.S.A. 14:E122-E131. doi: 10.1073/pnas.1611056113 
Miller, C. A., and Wyborn, C. (2020). Co-production in global sustainability: Histories and theories. Enviro. Sci. Policy 113, 88-95. doi: 10.1016/j.envsci.2018.01.016

National Oceanographic and Atmospheric Administration (NOAA) (2021). Sea Level Trends. Available online at: https://tidesandcurrents.noaa.gov/sltrends/ sltrends.html (accessed August 21, 2021).

Nordgren, J., Stults, M., and Meerow, S. (2016). Supporting local climate change adaptation: where we are and where we need to go. Environ. Sci. Policy 66, 344-352. doi: 10.1016/j.envsci.2016.05.006

Oliver, K., Kothari, A., and Mays, N. (2019). The dark side of coproduction: do the costs outweigh the benefits for health research? Health Res. Policy Syst. 17:33. doi: 10.1186/s12961-019-0432-3

O’Neill, A. C., Erikson, L. H., Barnard, P. L., Limber, P. W., Vitousek, S., Warrick, J. A., et al. (2018). Projected 21st century coastal flooding in the Southern California Bight. Part 1: development of the third generation CoSMoS model. J. Mar. Sci. Eng. 6:59. doi: 10.3390/jmse6020059

Overbeck, J. R (Ed.). (2018), Alaska Coastal Mapping Gaps \& Priorities. Fairbanks, AK: Alaska Division of Geological \& Geophysical Surveys Information Circular. doi: 10.14509/30096

Overbeck, J. R., Buzard, R. M., Turner, M. M., Miller, K. Y., and Glenn, R. J. (2020). Shoreline Change at Alaska Coastal Communities. Fairbanks, AK: Alaska Division of Geological \& Geophysical Surveys Report of Investigation. doi: $10.14509 / 30552$

Protection of the Arctic Marine Environment Arctic Council (2019). Meaningful Engagement of Indigenous Peoples and Local Communities in Marine Activities, Part II Report Findings for Policy Makers. Akureyri: Protection of the Arctic Marine Environment Arctic Council

Pulsifer, P., Stephenson, S., and Graybill, J. (2018). Introduction to the special issue 'community adaptation to changing weather and sea ice conditions'. Polar Geogr. 41, 237-240. doi: 10.1080/1088937X.2018.1543795

Reguero, B. G., Losada, I. J., and Méndez, F. J. (2019). A recent increase in global wave power as a consequence of oceanic warming. Nat Commun. 10:205. doi: 10.1038/s41467-018-08066-0

Rogers, E. (2019). Implementation of Sea Ice in the Wave Model SWAN, eds N. R. Laboratory. Arlington, VA: Naval Reseearch Laboratory, Ocean Dynamics and Prediction Branch, Oceanography Division.

Rolph, R. J., Mahoney, A. R., Walsh, J., and Loring, P. A. (2018). Impacts of a lengthening open water season on Alaskan coastal communities: deriving locally relevant indices from large-scale datasets and community observations. Cryosphere 12, 1779-1790. doi: 10.5194/tc-12-1779-2018

Rosales, J., Cady, C., Juday, G., Alix, C., Morimoto, M., Chapman, J., et al. (2021). Storm surge proxies in a data-poor landscape: a practical monitoring method for under-surveyed and -studied communities vulnerable to climate change. Clim. Change 164, 1-17. doi: 10.1007/s10584-021-02995-4

Shi, L., Chu, E., and Debats, J. (2015). Explaining progress in climate adaptation planning across 156 U.S. municipalities. J. Am. Plan. Assoc. 81, 191-202. doi: 10.1080/01944363.2015.1074526

SitNews (2011). No Special Session to Save Alaska's Coastal Zone Management Program. Ketchikan: Stories in the News. Available online at: http://www. sitnews.us/0511News/053111/053111_special_session.html (accessed May 29, 2021).

Stone, R. (2020). Indigenous Alaskans demand a voice in research on warming. Science 369:1284. doi: 10.1126/science.369.6509.1284

Stopa, J. E., Ardhuin, F., and Girard-Ardhuin, F. (2016). Wave climate in the Arctic 1992-2014: seasonality and trends. Cryosphere 10, 1605-1629. doi: $10.5194 /$ tc-10-1605-2016

Storlazzi, C. D., Reguero, B. G., Cumming, K. A., Cole, A. D., Shope, J. A., Gaido, L. C., et al. (2021). Rigorously Valuing the Coastal Hazard Risks Reduction Provided by Potential Coral Reef Restoration in Florida and Puerto Rico. Reston, VA: U.S. Geological Survey Open-File Report. doi: 10.3133/ofr20211054

Sweet, W. V., Kopp, R. E., Weaver, C. P., Obeysekera, J., Horton, R. M., Thieler, E. R., et al. (2017). Global and Regional Sea Level Rise Scenarios for the United States. Silver Spring, MD: NOAA/NOS Center for Operational Oceanographic Products and Services.

Thoman, R. L., Richter-Menge, J., and Druckenmiller, M. L. (2020). Arctic Report Card 2020 (Silver Spring, MD). doi: 10.25923/mn5p-t549

Thomson, J., Fan, Y., Stammerjohn, S., Stopa, J., Rogers, W. E., Girard-Ardhuin, F., et al. (2016). Emerging trends in the sea state of the Beaufort and Chukchi Seas. Ocean Model. 105, 1-12. doi: 10.1016/j.ocemod.2016.02.009
Toimil, A., Camus, P., Losada, I. J., and Alvarez-Cuesta, M. (2021). Visualising the uncertainty cascade in multi-ensemble probabilistic coastal erosion projections. Front. Mar. Sci. 8:683535. doi: 10.3389/fmars.2021.683535

Tuler, S., Dow, K., and Webler, T. (2020). Assessment of adaptation, policy, and capacity building outcomes from 14 processes. Environ. Sci. Policy 114, 275-282 doi: 10.1016/j.envsci.2020.09.003

U.S. Army Corps of Engineers (2006). Alaska Village Erosion Technical Assistance Program: An Examination of Erosion Issues in the Communities of Bethel, Dillingham, Kaktovik, Kivalina, Newtok, Shishmaref, and Unalakleet. Anchorage, AK: U.S. Army Corps of Engineers.

U.S. Army Corps of Engineers (2009). Alaska Baseline Erosion Assesment: Study Findings and Technical Report. Anchorage, AK: Elmendorf Air Force Base.

U.S. Congress (2007). "The state and federal response to storm damage and erosion in Alaska's coastal villages; hearings," in Senate Ad Hoc Subcommittee on Disaster Recovery of the Committee on Homeland Security and Governmental Affairs (Washington, DC: U.S. Government Printing Office).

U.S. Government Accountability Office (2020). Climate Change: A Climate Migration Pilot Program Could Enhandce the Nation's Resilience and Reduce Federal Fiscal Exposure. Washington, DC: GAO.

U.S. Interagency Arctic Research Policy Committee (2018). Principles for Conducting Research in the Arctic. Available online at: https://www. iarpccollaborations.org/uploads/cms/documents/principles_for_conducting _ research_in_the_arctic_final_2018.pdf

University of Alaska Fairbanks Institute of Northern Engineering, U.S. Army Corps of Engineers Alaska District, U.S. Army Corpos of Engineers Cold Regions Research and Engineering Laboratory (2019). Statewide Threat Assessment: Identification of Threats from Erosion, Flooding, and Thawing Permafrost in Remote Alaska Communities. Akureyri: University of Alaska Fairbanks Institute of Northern Engineering.

Wang, M., and Overland, J. E. (2015). Projected future duration of the sea-ice-free season in the Alaskan Arctic. Prog. Oceanogr. 136, 50-59. doi: $10.1016 /$ j.pocean.2015.01.001

Weaver, R. J., and Slinn, D. N. (2010). Influence of bathymetric fluctuations on coastal storm surge. Coast. Eng. 57, 62-70. doi: 10.1016/j.coastaleng.2009.09.012

Webler, T., Tuler, S., Dow, K., Whitehead, J., and Kettle, N. (2016). Design and evaluation of a local analytic-deliberative process for climate adaptation planning. Local Environ. 21, 166-188. doi: 10.1080/13549839.2014.93 0425

Wheeler, H. C., Danielsen, F., Fidel, M., Hausner, V., Horstkotte, T., Johnson, N., et al. (2020). The need for transformative changes in the use of indigenous knowledge along with science for environmental decision-making in the Arctic. People Nat. 2, 544-556. doi: 10.1002/pan3.10131

Wyborn, C., Datta, A., Montana, J., Ryan, M., Leith, P., Chaffin, B., et al. (2019). Co-producing sustainability: reordering the governance of science, policy, and practice. Annu. Rev. Environ. Resour. 44, 319-346. doi: 10.1146/annurev-environ-101718033103

Author Disclaimer: Any use of trade, firm, or product names is for descriptive purposes only and does not imply endorsement by the U.S. Government.

Conflict of Interest: The authors declare that the research was conducted in the absence of any commercial or financial relationships that could be construed as a potential conflict of interest.

Publisher's Note: All claims expressed in this article are solely those of the authors and do not necessarily represent those of their affiliated organizations, or those of the publisher, the editors and the reviewers. Any product that may be evaluated in this article, or claim that may be made by its manufacturer, is not guaranteed or endorsed by the publisher.

Copyright $\odot 2021$ Williams and Erikson. This is an open-access article distributed under the terms of the Creative Commons Attribution License (CC BY). The use, distribution or reproduction in other forums is permitted, provided the original author(s) and the copyright owner(s) are credited and that the original publication in this journal is cited, in accordance with accepted academic practice. No use, distribution or reproduction is permitted which does not comply with these terms. 